\title{
Simple and Sensitive Method of Fluorometry for Determination of Total Antioxidant Capacity
}

\author{
Saeed Nazeri ${ }^{1}$, Bahram Yaghmaie ${ }^{1}$, Mehdi Hedayati ${ }^{2}$ \\ 1. Department of Clinical Biochemistry, School of Medicine, Shahid Beheshti University of Medical Sciences, Tehran, Iran \\ 2. Cellular and Molecular Endocrinology Research Center, Institute of Endocrine Sciences, Shahid Beheshti University of Medical \\ Sciences and Metabolism, Tehran, Iran
}

Received:04 Mar 2018;Accepted:15 May 2018;

ABSTRACT

Background and Objective: Oxidative stress plays an important role in the pathogensis of various diseases, including lung cancer, chronic obstructive pulmonary disease, and atherosclerosis. Total antioxidant capacity plays a significant role in the body's antioxidant defense, so its assessment is a matter of the utmost importance. Currently, assessment of this capacity is performed in various scientific fields by expensive imported kits. The aim of the present study was to design a sensitive fluorometric method for the assessment of total antioxidant capacity and improvement of sensitivity, accuracy, and speed of the measurement.

Methods: The sensitivity and intra- and inter-assay accuracy, verification by recovery and parallelism tests, method comparison, and correlation and coherence evaluation were performed. To increase the accuracy and speed of reading, the assay was performed in a microplate and reading was done using a fluorometer plate.

Result: In accuracy assessment, intra- and inter-assay coefficient of variation was calculated to be 4.1-5.7 and 4.4-7.5, respectively. In validity evaluation, the recovery percentage was calculated to be $90-109$, the recovery percentage range was 90 to 109 . Comparison of the results of this method on 50 serum samples with common colorimetric method, indicated a good correlation (0.93). The sensitivity of the studied method was $0.01 \mathrm{mM} / 1$.

Conclusion: Microplate-reader fluorometry, in addition to increasing the speed of measurement, has enough efficacy, accuracy, and sensitivity to assess total antioxidant capacity and could be an appropriate alternative for current colorimetric methods.

Keywords: Fluorometry, Total antioxidant capacity, Microplate reading

Corresponding Information: Mehdi Hedayati, Cellular and Molecular Endocrinology Research Center, Institute of Endocrine Sciences, Shahid Beheshti University of Medical Sciences and Metabolism, Tehran, Iran; Email: Hedayati@endocrine.ac.ir

Copyright (C) 2018. This is an open-access article distributed under the terms of the Creative Commons Attribution-noncommercial 4.0 International License which permits copy and redistribute the material just in noncommercial usages, provided the original work is properly cited.

\section{Introduction}

Production of active species, such as free radicals is a part of human metabolism (1). Due to high-damage potential for vital biological systems, active species are responsible for aging and more than 100 diseases, including cardiovascular diseases (CVD), neurological disorders (Alzheimer and Parkinson), diabetes, and cancer (2-4). Antioxidants help cells to overcome oxidative stress through effective trapping of the free radicals and consequently prevent the disease $(5,6)$. Eating enough fruits and vegetables decreases the risk of diseases and 
it is recommend by most of the countries (7). This decrease is related to the presence of antioxidants (vitamin C, vitamin E, carotenoids, lycopene, and flavonoids) in fruits and vegetables, which help to prevent free radical damages. Antioxidant enzymes (AOE) include superoxide dismutase, catalase, and glutathione peroxidase and indirectly glutathione reductase $(8,9)$. Antioxidants can generally neutralize free radicals by giving an electron or at least inhibit the chain reactions that lead to tissue damage (10). Evaluation of plasma total antioxidant capacity is important for the diagnosis of diseases. Most conventional methods for evaluating total antioxidant capacity are making use of colorimetric reactions. In these reactions, the residual hydrogen peroxide produced from catalase enzyme activity, reacts with the chromogen. The amount of produced color has an inverse relationship with total antioxidant capacity (11). The sensitivity of emission methods, such as fluorimetry and luminometry is higher than absorption methods, such as colorimetric absorption $(12,13)$. The aim of this study was to design a sensitive fluorometric method for quick and simple assessment of total antioxidant capacity.

\section{Materials and methods}

An analytical scale (Sartorius, Germany), ELISA 96-well microplate reader (Sunrise, $\mathrm{GmbH}$, Tecan, Austria), a fluorometric 96-well microplate reader (BMG FLUOstar, Austria), and an acidometer machine (Mettler MP-220, Switzerland), were used in this research.

\section{Chemicals}

All required chemicals with high degree of purity, including sodium phosphate, disodium phosphate, AAPH $[2,2$ '-azobis (2-amidinopropane) dihydrochloride], dichlorodihydro-fluorescein diacetate (DCFH-DA, fluorogene) (14), and peroxidase enzyme were purchased from Merck and Sigma Company. Black 96-well fluorometric microplates were purchased from Nunc Company (Denmark) for comparing the results of the studied method with a common method, and total antioxidant capacity kit was obtained from Randox Company, (Crumlin, UK). Double-distilled water was prepared using a glass distillation apparatus with a conductivity of less than 0.01 microsiemens $(\mu \mathrm{S})$.

\section{Reaction buffer}

phosphate buffer (100 mM, pH 7.4) and Tris buffer $(100 \mathrm{mM}, \mathrm{pH} 7.8)$ were prepared and stored at $2-8^{\circ} \mathrm{C}$.

\section{AAPH initiator solution}

Stock solution $(100 \mathrm{mM})$ was stored at $2-8^{\circ} \mathrm{C}$. Fresh solution $(10 \mathrm{mM})$ was prepared from phosphate buffer.

\section{TAC standard solution with a defined activity}

Ethanolic solution of Trolox $(10 \mu \mathrm{M})$ was stored at $\left.-20^{\circ} \mathrm{C}\right)$. Fresh solution $(1 \mathrm{mM})$ was prepared from phosphate buffer.

\section{Fluorogenic substrate solution}

Solutions at concentration of $1 \mathrm{mM}$ were prepared using dimethyl sulfoxide (DMSO) as solvent and reaction buffer and stored at $-20^{\circ} \mathrm{C}$. Fresh solutions were used at a concentration of $10 \mathrm{mM}$. The solution was photosensitive and prepared and kept in dark or aluminum foil wrapped containers.

\section{The study sample}

A total of 50 serum samples $(5 \mathrm{ml})$ were taken from healthy volunteers referred to Taleghani Hospital for health checkup. The blood samples 
were drawn into conventional tubes, incubated for $10 \mathrm{~min}$ at room temperature, and then centrifuged at $3500 \mathrm{rpm}$ for $15 \mathrm{~min}$ to separate their serum.

\section{Optimization of experiment method}

Optimum conditions (time, AAPH concentration, fluorogene concentration) were determined in 5 samples according to recovery test as follow:

To assess the total antioxidant capacity, $10 \mu 1$ of the serum sample and $50 \mu 1$ of AAPH sample were added to each well of fluorescence reader 96-well microplate (Nunc C, Denmark); the plate was incubated at $37^{\circ} \mathrm{C}$ for $15 \mathrm{~min}$; then, $100 \mu \mathrm{l}$ of fluorogenic dihydrofluorescein diacetate was added to the wells and after 15 min incubation at $37^{\circ} \mathrm{C}$, the fluorometric reading was performed with excitation at $485 \mathrm{~nm}$ and emission at 535 nm. The standard curve was drawn with the level of fluorescence signals as Y-axis and total antioxidant capacity as $\mathrm{X}$-axis.

Optimum conditions (time, AAPH concentration, and fluorogene concentration) were determined based on the recovery test in 5 samples as follows: In each microplate, standards were used with the concentrations of $0,0.05,0.1,0.15,0.2,0.25$, and $0.5 \mu \mathrm{g} / \mu \mathrm{l}$. The standard curve was drawn with logarithm of the mean fluorescence signals of the standards as the Y-axis and total antioxidant capacity of the standards as the $\mathrm{X}$-axis. Total antioxidant capacity was calculated using linear regression analysis of the above curve. Deionized doubledistilled water was used as the zero standard. The activity related to mean zero standard signal with 10 times repetition plus double standard deviation, was established as a basis for determining the detection limit of this method. Serial dilution of a serum sample was used for confirmation. Deionized double-distilled water was used for dilution.

To evaluate the accuracy of the method, intra and inter-assays of samples with low, medium, and high concentrations with an 8 -time repetition, were used.

Evaluation of total antioxidant capacity after adding different standards to 6 random samples with a 3-time repetition, was established as a basis for the recovery test. The increase of zero standard was used as control.

The evaluation of total antioxidant capacity in 6 samples with low, medium, and high concentration after the serial dilution with a 3-time repetition was established as the basis for the parallelism test. The results of this method and colorimetric method were investigated in 50 samples.

\section{Statistical analysis}

The obtained data were analyzed using SPSS software. Quantitative variables were presented as mean \pm standard deviation. Pearson regression test was used to compare the two methods. As mentioned earlier, the percentage of variation coefficient was used to indicate the accuracy of the two method.

\section{Results}

In different conditions of time, AAPH concentration, and fluorogene concentration, the recovery of total antioxidant capacity in 5 samples showed that $15 \mathrm{~min}$ of time, $50 \mu \mathrm{l}$ concentration of AAPH, and $100 \mu$ concentration of fluorogene were considered as optimum conditions.

The detection limit was determined to be 0.01 $\mathrm{mM} / 1$ according to the concentration of mean zero standard signal with a 10 -times repetition plus its double standard deviation.

The internal test percentage of intra-assay coefficient variations in samples with low, medium, and high concentrations was calculated to be 5.7, 4.1, and 5.3, respectively. These coefficients for inter-assay were 7.5, 4.4, and 6.7, respectively (Table 1 and 2). 


\section{Fluorometry in Determining Total Antioxidant Capacity}

Table 1

Results obtained from the evaluation of internal test coefficient of variation and total antioxidant capacity using fluorometry method and microplate reading through an 8 -time repetition

\begin{tabular}{ccc}
\hline $\begin{array}{c}\text { The percentage Mean coefficient of } \\
\text { variation }(\mathbf{m m o l} / \mathbf{l})\end{array}$ & Standard deviation & Number of repetitions \\
\hline 5.7 & 0.0057 & 8 \\
0.1 & 0.0102 & 8 \\
\hline 4.1 & 0.0265 & 8 \\
\hline 5.25 & & 8 \\
\hline
\end{tabular}

Table 2

Results obtained from the evaluation of external test coefficient of variation and total antioxidant capacity using fluorometry method and microplate reading through an 8 -time repetition

\begin{tabular}{ccc}
\hline $\begin{array}{c}\text { The percentage Mean coefficient of } \\
\text { variation }(\mathbf{m m o l} / \mathbf{l})\end{array}$ & Standard deviation & Number of repetitions \\
\hline 7.5 & 0.0075 & 8 \\
0.1 & 0.011 & 8 \\
\hline 4.4 & 0.0335 & 8 \\
\hline 0.25 & & 8 \\
\hline
\end{tabular}

Table 3

Results obtained from the recovery test in evaluation of total antioxidant capacity using fluorometry method and microplate reading

\begin{tabular}{|c|c|c|}
\hline $\begin{array}{c}\text { The percentage measured } \\
\text { recovery }\end{array}$ & $\begin{array}{c}\text { Sample concentration }(\mathrm{mmol} / \mathrm{l}) \\
\text { Standard }(\mathrm{mmol} / \mathrm{l})\end{array}$ & Expected rate \\
\hline \multirow{3}{*}{$\begin{array}{c}109 \\
0.125\end{array}$} & 0.136 & \multirow{3}{*}{2} \\
\hline & 0.05 & \\
\hline & 0.141 & \\
\hline 94 & 0.1 & \multirow{2}{*}{2} \\
\hline 0.150 & 0.215 & \\
\hline 107 & 0.2 & \multirow{2}{*}{2} \\
\hline 20 & 0.225 & \\
\hline 90 & 0.3 & 2 \\
\hline 0.25 & - & - \\
\hline 105 & 0.366 & 2 \\
\hline 0.35 & 0.5 & - \\
\hline
\end{tabular}


Table 3

Results obtained from the parallel test in evaluation of total antioxidant capacity using fluorometry method and microplate reading

\begin{tabular}{ccc}
\hline Expected ratio $(\mathbf{m m o l} / \mathbf{l})$ & Dilution & Measurement (mmol/l) \\
\hline 100 & 1 & 1.00 \\
1.00 & 2 & 0.53 \\
1.06 & 4 & 0.27 \\
0.50 & - & 0.118 \\
\hline 1.08 & 8 & - \\
\hline 0.25 & - & 0.069 \\
\hline 0.94 & 16 & - \\
\hline 0.125 & - & 0.033 \\
\hline 1.11 & 32 & - \\
\hline 0.062 & 169 & -030 \\
\hline
\end{tabular}

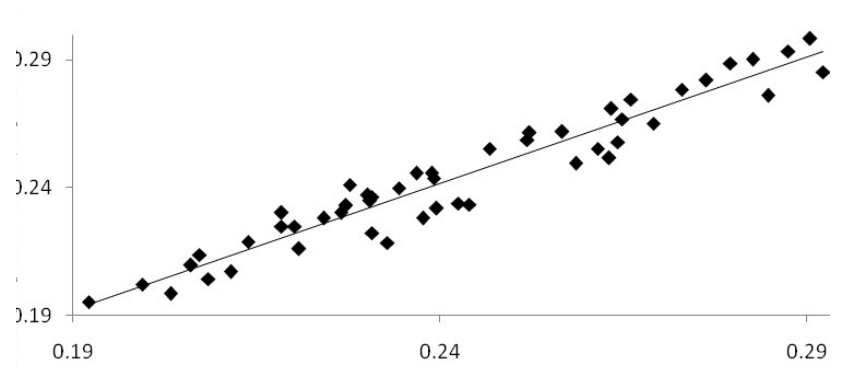

Fig. 1

Comparing the results of total antioxidant capacity evaluation by fluorometry method and microplate reading with the conventional colorimetric kit method in 50 serum samples

As can be seen in Table 3, the recovery of 6 samples was calculated to be $90-109 \%$. The ratio of measured concentration to expected concentration after serial dilution up to $1: 32$ was obtained 0.94 to 1.08 (Table 4).

Regression analysis between the results of fluorometric method and the comon

colorimetric method showed a good correlation $(\mathrm{r}=0.93)($ Fig. 1).

\section{Discussion}

Currently, evaluation of total antioxidant capacity has attracted a lot of attention, because antioxidant depletion can lead to various diseases (15). In the recent years, several methods have been reported for the evaluation of total antioxidant capacity $(16,17)$. This evaluation could be useful for prediction of the risk of tissue damage induced by free radicals (18). Kao and Pryor (1998), compared three assessment methods of Oxygen Radical Absorption Capacity (ORAC), Trolox equivalent antioxidant capacity (TEAC), and ferric reducing antioxidant power (FRAP) for total antioxidant capacity evaluation. FRAP assay is simple and low-cost, cannot measure the antioxidants containing thiol group (-SH). ORAC assay has high specificity and responds to various antioxidants, but needs 60 min more than the two other assays to give the results (12).

Ziyatdinova etal.(2006), devised a continuousflow colorimetric method to determine total antioxidant capacity in human plasma according to reaction of plasma antioxidants with electrogenerated bromine (19).

Wayner et al. (1985), for the first time reported the development of total radical-trapping 
antioxidant parameter (TRAP) method, in which sample volume is used to determine peroxyl radical absorption capacity related to antioxidants in biofluids. Peroxyl radicals are produced by thermal decomposition of AAPH at a constant velocity. In this assessment, beta-phycoerythrin fluorescent reagent is used for quick reaction of antioxidants with peroxyl radicals. Reduction kinetics of beta-phycoerythrin fluorescence provide information about the amount of (per) oxidative damage and scavenging activity of antioxidants' peroxyl radical (20). Gaboraiu et al. (2002), developed autoxidation homovanillic acid (HVA) method to determine antioxidant capacity of plasma or other biofluids, in which a sample of $2 \mathrm{ml}$ is incubated at $37^{\circ} \mathrm{C}$, and fluorescence is measured every $5 \mathrm{~s}$ at excitation wavelength of $315 \mathrm{~nm}$ and at emission wavelength of 425 $\mathrm{nm}$ for the subsequent 100 seconds (21). In ORAC method, all active defensive antioxidants, including non-protein antioxidants and most of the protein antioxidants are oxidized. Among numerous types of oxygen radicals produced in the body, peroxyl radical may not be biologically the most appropriate one (22).

In this study, given the importance of the total antioxidant capacity evaluation, this capacity was assessed in human serum samples using fluorometric method. In this research, three separately reported approaches of improvement of total antioxidant capacity evaluation, were used after optimization to finally develop a method consisting of all the above-mentioned advantages.

In the first approach, most of the reported methods and available kits have taken advantage of different colorimetric methods and dyes that mostly have low solubility. In this method, however, fluorescence signaling system derived from fluorogenic oxidation, has been used to increase the accuracy, and in contrast to insoluble dyes, is more soluble in aquatic environment and produces more signals. In the second approach, the assessmnet and reading were carried out in a 96-well microplate to increase the accuracy. This change improved accuracy and repeatability of the results in addition to decrease in total experiment time.

\section{Acknowledgement}

The present article was adapted from a clinical biochemistry master's thesis No. 362, approved by Shahid Beheshti University of Medical Sciences, Tehran, Iran.

\section{Conflict of interest}

The authors declare that there is no conflict of interests

\section{References}

1. Lobo V, Patil A, Phatak A, Chandra N. Free radicals, antioxidants and functional foods: Impact on human health. Pharmacogn Rev 2010;4(8):118-26.

2. Ames BN, Shigenaga MK, Hagen TM. Oxidants, antioxidants, and the degenerative diseases of aging. Proc Natl Acad Sci U S A 1993;90(17):7915-22.

3. Halliwell B, Gutteridge JM, Cross CE. Free radicals, antioxidants, and human disease: where are we now? J Lab Clin Med 1992;119(6):598-620.

4. Zhang PY, Xu X, Li XC. Cardiovascular diseases: oxidative damage and antioxidant protection. Eur Rev Med Pharmacol Sci. 2014;18(20):3091-6.

5. Pham-Huy LA, He H, Pham-Huy C. Free radicals, antioxidants in disease and health. Int $\mathrm{J}$ Biomed Sci 2008;4(2):89-96.

6. Jain AK, Mehra NK, Swarnakar NK. Role of Antioxidants for the Treatment of Cardiovascular Diseases: Challenges and Opportunities. Curr Pharm Des. 2015;21(30):4441-55.

7. Boeing H, Bechthold A, Bub A, Ellinger S, Haller D, Kroke A, et al. Critical review: vegetables and fruit in the prevention of chronic diseases. Eur J Nutr 2012;51(6):63763.

8. Wang X, Ouyang Y, Liu J, Zhu M, Zhao G, Bao W, et al. Fruit and vegetable consumption and mortality from 
all causes, cardiovascular disease, and cancer: systematic review and dose-response meta-analysis of prospective cohort studies. BMJ 2014;349:g4490.

9. Nkambo W, Anyama NG, Onegi B. In vivo hypoglycemic effect of methanolic fruit extract of Momordica charantia L. Afr Health Sci 2013;13(4):933-9.

10. Campanella L, Bonanni A, Bellantoni D, Favero G, Tomassetti M. Comparison of fluorimetric, voltammetric and biosensor methods for the determination of total antioxidant capacity of drug products containing acetylsalicylic acid. J Pharm Biomed Anal 2004;36(1):919.

11. Apak R, Guclu K, Ozyurek M, Karademir SE, Altun M. Total antioxidant capacity assay of human serum using copper(II)-neocuproine as chromogenic oxidant: the CUPRAC method. Free Radic Res 2005;39(9):949- 61.

12. Cao G, Prior RL. Comparison of different analytical methods for assessing total antioxidant capacity of human serum. Clin Chem 1998;44(6 Pt 1):1309-15.

13. Chapple IL, Mason GI, Garner I, Matthews JB, Thorpe GH, Maxwell SR, et al. Enhanced chemiluminescent assay for measuring the total antioxidant capacity of serum, saliva and crevicular fluid. Ann Clin Biochem 1997;34 (Pt 4):412-21.

14. Aranda A, Sequedo L, Tolosa L, Quintas G, Burello E, Castell JV, et al. Dichloro-dihydro-fluorescein diacetate (DCFH-DA) assay: a quantitative method for oxidative stress assessment of nanoparticle-treated cells. Toxicol In Vitro 2013;27(2):954-63.

15. McCormack D, McFadden D. A review of pterostilbene antioxidant activity and disease modification. Oxid Med Cell Longev 2013;2013:575482.

16. Jayawardena N, Watawana MI, Waisundara VY.
Evaluation of the total antioxidant capacity, polyphenol contents and starch hydrolase inhibitory activity of ten edible plants in an in vitro model of digestion. Plant Foods Hum Nutr 2015;70(1):71-6.

17. Shomali S, Avval FZ, Boostani R, Jarahi L, Youssefi M. Serum total antioxidant capacity status of HTLV-1 infected patients. Acta Virol 2015;59(2):199-203.

18. Chang CC, Lee CT, Lan TH, Ju PC, Hsieh YH, Lai TJ. Effects of antidepressant treatment on total antioxidant capacity and free radical levels in patients with major depressive disorder. Psychiatry Res 2015;230(2):575-80.

19. Ziyatdinova GK, Budnikov HC, Pogorel'tzev VI. Electrochemical determination of the total antioxidant capacity of human plasma. Anal Bioanal Chem 2005;381(8):1546-51.

20. Wayner DD, Burton GW, Ingold KU, Locke S. Quantitative measurement of the total, peroxyl radicaltrapping antioxidant capability of human blood plasma by controlled peroxidation. The important contribution made by plasma proteins. FEBS lett 1985;187(1):33-7.

21. Gaboriau F, Delcros JG, Moulinoux JP. A simple assay for the measurement of plasma antioxidant status using spontaneous autoxidation of homovanillic acid. J Pharmacol Toxicol Methods 2002;47(1):33-43.

22. Cao G, Prior RL. Measurement of oxygen radical absorbance capacity in biological samples. Methods Enzymol 1999;299:50-62.

\section{How to cite this article}

Nazeri S, Yaghmaie B, Hedayati M. Simple and Sensitive Method of Fluorometry for Determination of Total Antioxidant Capacity. Mod Med Lab J. 2018;1(1):29-35. 